\title{
IDENTIFICAÇÃO DE ELEMENTOS DA POLUIÇÃO RURAL E URBANA EM UMA BACIA HIDROGRÁFICA DE PEQUENO PORTE
}

\author{
Renato Emanuel Silva ${ }^{1}$ \\ Washington Luiz Assunção ${ }^{2}$
}

\begin{abstract}
RESUMO
O presente trabalho tem por objetivo identificar elementos da poluição de origem rural e urbana em uma bacia de pequeno porte. A apropriação de espaços por atividades urbanas e rurais constitui um grande fator de impacto sobre os recursos hídricos e demanda ações que apontem as condições destes espaços, como neste estudo de caso. Para tanto foram realizadas atividades de campo que buscaram identificar impactos ambientais e fontes de poluição na área pesquisada. Os dados foram registrados e plotados em um produto cartográfico síntese. Como elementos a serem localizados foram elencados lançamento de efluentes, granjas, depósitos irregulares e fossas negras. A pesquisa revela que os setores da bacia hidrográfica ligados ou próximos ao perímetro urbano são aqueles com maior quantidade de impactos, sendo identificadas todas as categorias investigadas. Já a bacia voltada ao abastecimento urbano de Patrocínio (MG) possui uma melhor conservação, sendo apontadas apenas fossas negras na área. Deste modo a existência de duas áreas, uma melhor preservada que outra, sugere a necessidade de implementação de um plano de gestão ambiental para toda a bacia pesquisa, buscando mitigar os impactos nela encontrados e garantindo a qualidade dos recursos hídricos e dos demais elementos ambientais.
\end{abstract}

PALAVRAS-CHAVE: Fontes de Poluição. Bacia hidrográfica rural e urbana, Patrocínio-MG

\section{IDENTIFICATION OF RURAL AND URBAN POLLUTION OF ELEMENTS IN A SMALL BASIN PORTE}

\begin{abstract}
This study aims to identify pollution elements of rural and urban origin in a small watershed. The appropriation of spaces for urban and rural activities is a major impact factor on water resources and demand actions that point the conditions of these spaces, as in this case study. Research was carried out in the field who have sought to identify environmental impacts and pollution sources in the area surveyed. Data were recorded and plotted on a map. As elements to be located were listed effluent discharge, farms, irregular deposits and conventional cesspool. The survey reveals that the sectors of connected or close to the urban area watershed are those with higher impacts, identified all investigated. Already the basin focused on the urban supply Patrocínio (MG) has a better conservation, being identified only conventional cesspool in the area. Thus the existence of two areas, better preserved than another, suggests the need to implement an environmental management plan for the whole basin research, seeking to mitigate the impacts it found and ensuring the quality of water resources and other environmental elements.
\end{abstract}

KEYWORDS: pollution source. Rural and urban watershed, Patrocínio (MG)

\footnotetext{
${ }_{1}^{1}$ Mestre em Planejamento Ambiental, IG/UFU - renato.logan@gmail.com

2 Doutor em Geografia, IG/UFU. E-mail.wlassuncao@gmail.com
} 


\section{IDENTIFICACIÓN DE LA CONTAMINACIÓN RURAL Y URBANO DE ELEMENTOS EN UN PEQUEÑO CUENCA DEL PORTE}

\section{RESUMEN}

Este estudio tiene como objetivo identificar elementos de la contaminación de origen rural y urbana en un tazón pequeño. La apropiación de espacios para actividades urbanas y rurales es un factor de gran impacto en los recursos hídricos y la demanda que señalan las condiciones de estos espacios, como en este caso de estudio. Tanto para las actividades de campo se llevaron a cabo de que trató de identificar los impactos ambientales y las fuentes de contaminación en el área estudiada. Los datos fueron registrados y se representan en uno mapa. Como elementos que se encuentran se enumeraban la descarga de efluentes, granjas, depósitos irregulares y fossa convencional. La encuesta revela que los sectores de conectado o cerca del área de la cuenca urbana son aquellos con impactos más altos, identificado todos investigado. Ya la cuenca centrado en el Patrocinio abastecimiento urbano (MG) tiene una mejor conservación, siendo identificado sólo fossa convencional en la zona. Así, la existencia de dos zonas, una mejor conservados de otro, sugiere la necesidad de implementar un plan de gestión ambiental para toda la cuenca investigación, tratando de mitigar los impactos que se han encontrado y la garantía de la calidad de los recursos hídricos y otros elementos ambientales.

PALABRAS CLAVE: Fuente de contaminación. Cuenca rural y urbano, Patrocinio MG

\section{INTRODUÇÃO}

O avanço das populações humanas, sobre as mais diversas paisagens do globo, têm contribuído para o agravamento do quadro de impactos ambientais. Os recursos naturais são massivamente captados e exauridos nos mais diversos contextos potencializados pelo consumo humano. Tamanha pressão gera uma série de efeitos coletareis (Drew, 1984), como aqueles relativos a água, recurso fundamental, que vem tendo sua disponibilidade explorada a exaustão.

A condição de diversas formas de apropriação da água geram uma multiplicidade de impactos como desperdícios e contaminação de corpos hídricos. Assim agricultura, pecuária, pesca, criação de peixes e outros animais aquáticos, lazer, indústria, mineração, navegação, estética paisagística e abastecimento urbano demandam avaliações especificas conforme as realidades existentes e os objetivos para mitigação de impactos e gestão futura (Tundisi e Tundisi, 2011).

Os desperdícios revelam a falta de conscientização dos usuários e a ausência de planos de gestão eficientes para conservação, captação, transporte e distribuição da água (Hoekstera, 2011). Deste modo a constante pressão sobre a captação ou utilização da água não significa o atendimento igualitário de todas as 


\section{$=-5$

comunidades demandantes do recurso. Ao contrário é cada vez maior o número de grupos humanos que vivenciam a crise hídrica.

A contaminação, por sua vez envolve situações onde produtos agrícolas, principalmente ligados ao controle de pragas, doenças e adubação chegam até os canais ou contaminam as águas subterrâneas. Também as cidades podem ser produtoras de fontes de contaminação, principalmente através do lançamento de efluentes domésticos, comerciais e industriais. Percebe-se que as fontes de poluição estão estreitamente ligadas com o avanço e diversificação agrícola bem como o crescimento urbano (Tundisi e Tundisi. 2011). As contaminações de águas subterrâneas e superficiais sugere a indisponibilidade do recurso para o consumo humano além de condenar a funcionalidade ecossistêmica dos manciais.

Surge, no contexto de apropriação da água, uma demanda por planos de gestão ambiental, uma vez que é grande a dificuldade de estabelecer uma relação eficiente entre sociedade e ecossistemas aquáticos e terrestres. O planejamento ambiental surge como uma premissa para organizar o espaço, no qual a comunidade se relaciona com o meio natural, norteada pela necessidade de manutenção dos recursos naturais e do bem estar social, Santos (2004). Conforme Silva (2000) o planejamento parte do levantamento de dados, diagnóstico da realidade, integração dos resultados e proposição final.

Estudos que objetivam levantamentos e realização de planos de gestão ambiental necessitam de uma unidade espacial concisa. Para esses fins a escolha da bacia hidrográfica se justifica pela possibilidade de percepção das atividades humanas impactantes por meio da avaliação da qualidade e quantidade da água no exutório do canal principal da bacia hidrográfica, ou em outros pontos. Nesse caso predomina a ótica de uma área delimitada por divisores topográficos que pode ser estudada como sistema integrado (Tucci e Mendes, 2006).

As atividades rurais e urbanas são neste caso causadoras de impacto e devem ser avaliadas considerando medidas para mitigação ou interrupção dos elementos geradores de problemas. As realidades de bacias hidrográficas em áreas de contato rural/urbano constituem um típico cenário para pesquisa e proposição de intervenções a partir da realidade dos problemas ambientais nelas existentes. Este é o caso do Alto Curso do rio Dourados, localizada em Patrocínio-MG (Mesorregião do Triangulo Mineiro/Alto Paranáiba), que além de desempenhar função de 


\section{Periódica Eletranica

abastecimento urbano, atente uma agricultura diversificada, e sofre os impactos da intervenção humana, principalmente no que se refere a produção de resíduos sólidos e contaminantes hídricos.

O rio Dourados é afluente da margem esquerda do rio Paranaíba e tem suas nascentes na região de contato entre o meio urbano e rural de Patrocínio - MG. Suas águas são exploradas pela pesca, lazer, irrigação, dessedentação animal, abastecimento urbano e rural (Silva et al 2012). A área de estudo deste trabalho se trata do alto curso do rio Dourados (Mapa 1) que possui $198 \mathrm{~km}^{2}$ de extensão. O alto curso do rio Dourados é usualmente dividida em duas sub-bacias, onde $100 \mathrm{~km}^{2}$ correspondem a região das nascentes do rio Dourados e $98 \mathrm{~km}^{2}$ se referem a curso do córrego Feio. Tal divisão se justifica pelas características físicas e humanas dentro das duas sub-bacias (Silva 2014). A confluência das águas do rio Dourados e do Córrego Feio ocorre no exutório da área de pesquisa.

O clima, conforme aponta Mendes (2008), é marcado por duas estações, o inverno seco e ameno contrasta com o verão quente e úmido. O regime climático, estabelecido pela alternância destas estações, apresenta média pluviométrica de $1477(\mathrm{~mm})$ anuais concentradas no verão de outubro a março. Quanto às médias térmicas, o verão apresenta cerca de $23^{\circ} \mathrm{C}$ e o inverno entre 18 e $19^{\circ} \mathrm{C}$.

A bacia se encontra entre duas estruturas distintas, o Domo de Serra Negra de origem Mesozoica que abriga as principais nascentes do rio Dourados, apresentando relevo íngreme nas áreas das nascentes, com altitudes variando de 1000 a 1250 metros, seguido de uma área com depósitos aluvionares em torno dos 800 metros (Casseti, 1984). Esta porção da bacia foi intensamente ocupada por atividades agrícolas diversificadas, destacando-se o café, milho, horticultura e pecuária. No últimos 30 anos a bacia vem sendo gradativamente integrada por espaços urbanos, deste modo a paisagem da região encontra-se fragmentada por bairros e propriedades rurais de pequeno porte. Já o córrego Feio nasce e percorre uma área do Arco da Canastra com micaxistos e quartzitos em sua litologia (Machado. 2002). O relevo acidentado desta área e os fundos de vale encaixados dificultaram a ocupação humana, permitindo uma maior conservação deste córrego que justamente abastece a cidade de Patrocínio-MG. 


\section{Fórum Ambiental}

da Alta Paulista

Volume 11, Número 06, 2015

Planejamento e Gestão dos Recursos Hídricos

Mapa 1: Localização da bacia do rio Dourados - em destaque a área de estudo correspondente ao alto curso desta bacia.

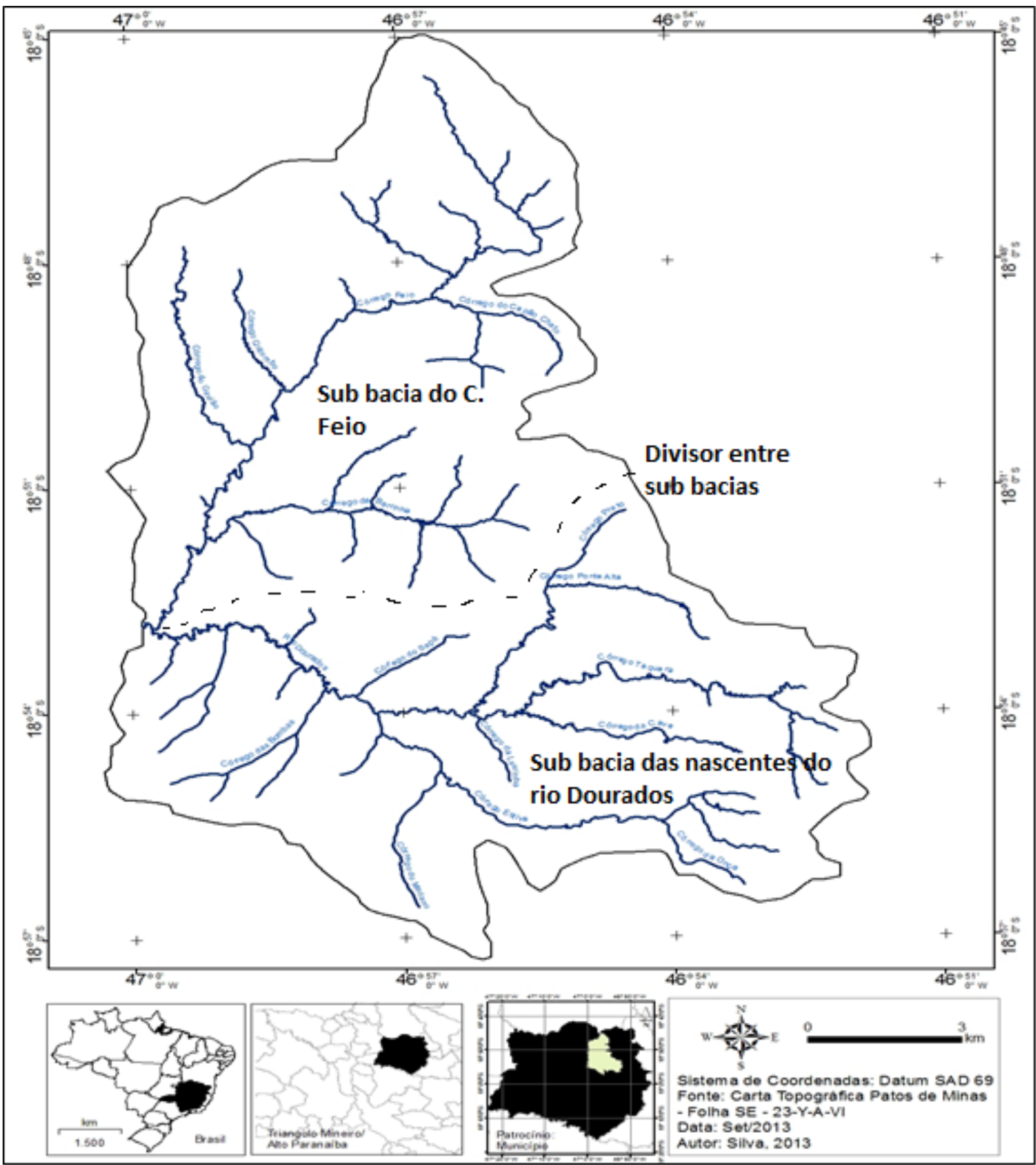




\section{OBJETIVO}

É objetivo deste trabalho apontar as áreas que apresentam casos de poluição, dentro da bacia do alto curso do rio Dourados (Patrocínio - MG), para efluentes, fossas negras e depósitos de lixo.

\section{MÉTODOS DE ANÁLISE}

Com o objetivo de localizar as diversas fontes poluidoras, presentes na bacia hidrográfica, foram realizados trabalhos de campo que permitiram confirmar as suposições existentes sobre diversos impactos recorrem na área de estudo. Nesta fase o dialogo estabelecido com os moradores do perímetro rural e urbano foi essencial para identificação destas fontes.

A abordagem da paisagem foi realizada tendo como proposta metodológica as reflexões de Francisco Mendonça (1999) para diagnósticos em pequenas bacias. Neste caso foram utilizados as estradas e trilhas para atingir o maior número de setores da bacia. Todos os impactos foram marcados por GPS e posteriormente plotados em um mapa de síntese dos elementos poluidores.

As fossas negras foram classificadas a partir da presença de sedes rurais. Para as áreas de lançamento de efluentes (esgoto residencial) avaliou-se a condição da água dos cursos fluviais a partir da pesquisa de Malagoli (2013) que apontou contaminantes característicos de fontes poluentes desta tipologia. Em campo constatou-se o lançamento de efluentes.

Para o mapeamento das fontes de poluição existentes na bacia, se fez necessário o uso de duas imagens do sensor Blackbrigde 2010 (com a composição colorida BGR para as bandas Red - (630 á $690 \mu \mathrm{m})$, Green (520 á $590 \mu \mathrm{m}$ ); Near IR $(0,76-1,2 \mu \mathrm{m}))$. Realizou-se a identificação de possíveis fontes poluidoras e locais com maior tendência a abriga-las por meio da interpretação visual (através da tela de computador seguindo os passos propostos por Veloso et al (2013)). A rede de drenagem seguiu o produto cartográfico do IBGE 1979 (Cartas planimétricas da região).

A construção dos apontamentos da imagem de satélite e atividade de campo foi realizada no software Arc Gis Map 9, de propriedade do Instituto de Geografia da 
Universidade Federal de Uberlândia, por meio do recorte da área de interesse. Por fim foi elaborado um quadro de indicadores de impactos ambientais, sugerido pelo Ministério do Meio Ambiente em 2005 e adaptado para a realidade da bacia em questão.

\section{RESULTADOS E DISCUSSÕES}

Durante os trabalhos de campo observou-se diferenças entre as condições de ocupação das nascentes rio Dourados e do Córrego Feio. A apresentação dos dados no mapa 2 permite conhecer tal realidade.

Em primeiro lugar analisa-se os depósitos irregulares de lixo. Embora exista no perímetro urbano de Patrocínio a coleta diária de lixo muitos são aqueles que, clandestinamente, tem realizado o descarte de materiais de construção, tecidos, papeis e plásticos em áreas inapropriadas. Tucci e Mendes apontam que o lixo é uma realidade problemáticas em área de expansão urbana

(...) um outro problema aparece, que é a produção de lixo. O lixo obstrui ainda mais a drenagem e cria condições ambientais ainda piores. Esse problema somente é minimizado com adequada frequência da coleta, educação da população e penalidades para depósito e lançamento de lixo irregular. (TUCCl; MENDES, 2006, p.26)

O lixo e o entulho constituem sérios problemas, sendo catalizadores de doenças, como aquelas propagadas por pragas. A contaminação do ar, solo e água também são uma realidade (Praxedes et al, 2010). É comum encontrar lixo em terrenos não ocupados e principalmente nas bordas dos bairros e nos manciais (fotos 1 e 2). Nas áreas de contato entre rural e urbano são observados 0 lançamento de lixo e rejeitos da construção civil. A região do bairro Serra Negra e a área do aeroporto, ambas inseridas no setor bacia referente as nascentes do rio Dourados, são marcadas por estas realidades. 


\section{Fórum Ambiental}

Volume 11, Número 06, 2015

da Alta Paulista

Planejamento e Gestão dos Recursos Hídricos

Mapa 2: Alto curso da bacia hidrográfica Fontes poluidoras

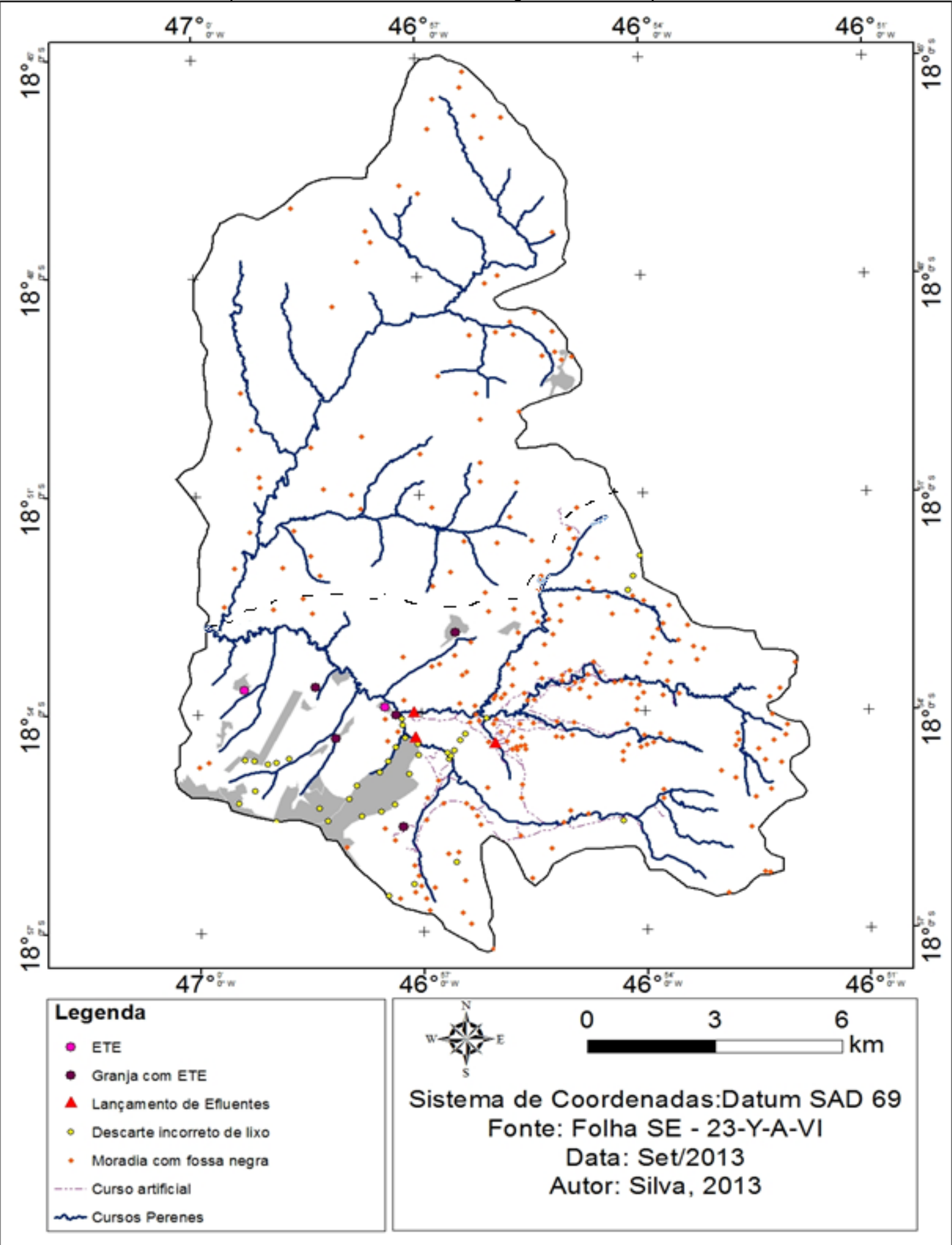




\section{Periódica Eletrânica

Foto 1: Alto curso da bacia do rio Dourados: Lixo encontrado dentro do córrego da Estiva - Bairro Serra Negra

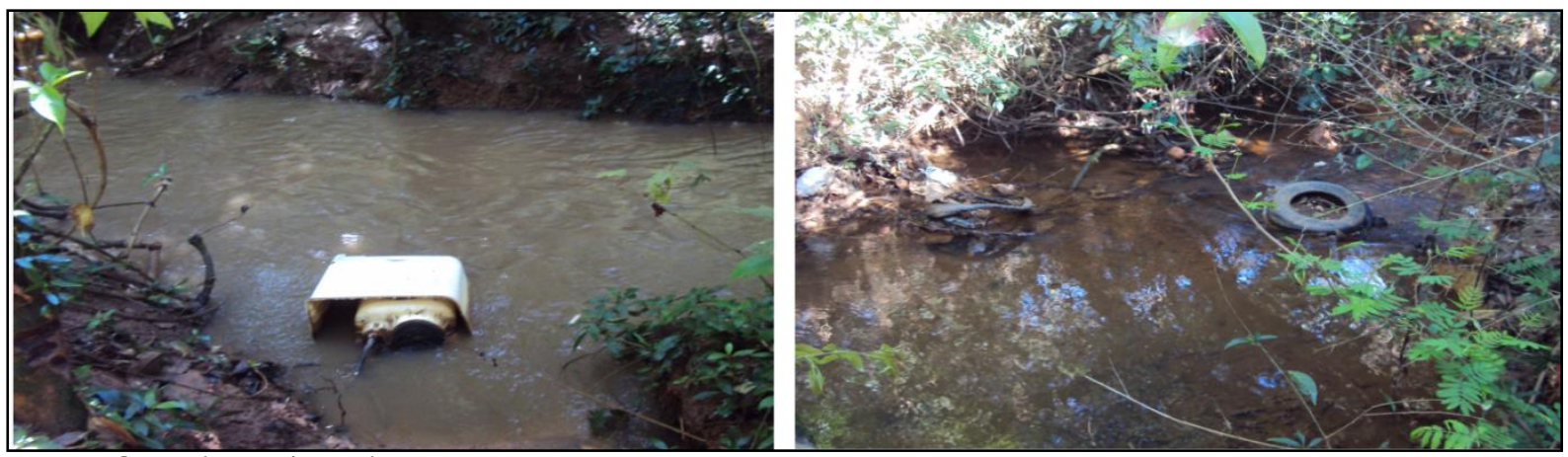

Fonte: Silva (2012/2013)

Já as áreas rurais apresentam depósitos irregulares principalmente de materiais plásticos, tecidos, papeis entre outros utensílios domésticos. São encontrados depósitos, principalmente, ao longo da estrada que liga a rodovia 365 ao bairro Serra Negra. em alguns pontos o lixo foi descartado dentro de mananciais de água. O fato do lixo estar depositado as margens de uma estrada de acesso urbano, pode sugerir que estes depósitos são originados da cidade de Patrocínio. Em campo foram identificadas que os moradores rurais da bacia preferem queimar ou enterrar os resíduos produzidos por eles. Salienta-se aqui que queimadas ou soterramento dos resíduos não é ideal uma vez que também gera impacto relativos a contaminação do solo, águas subterrâneas e o ar.

Foto 2: Alto curso da bacia do rio Dourados: Depósito de lixo próximo ao Bairro Cruzeiro e de construção civil bairro Serra Negra

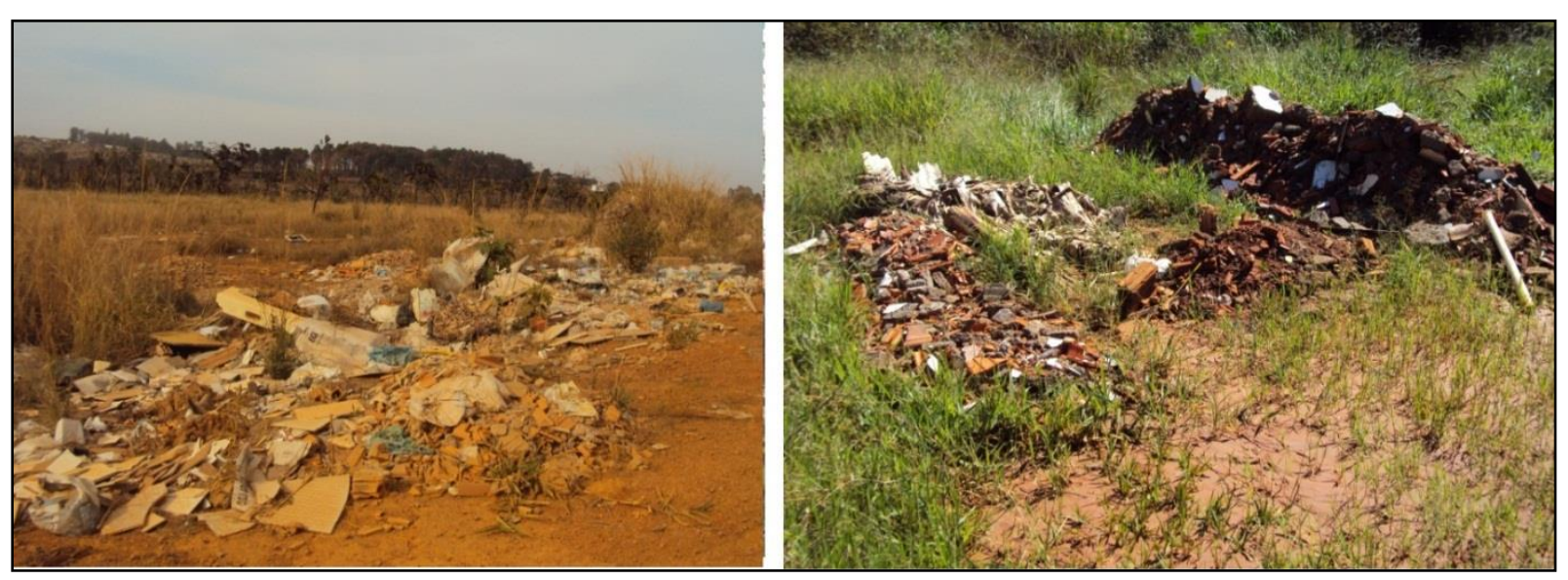

Fonte: Silva (2012/2013) 


\section{Periádica Eletrânica

Ao longo dos trabalhos de campo, realizados entre 2012 e 2014, não foram encontrados nenhum deposito de lixo na porção norte que corresponde a bacia do córrego Feio. O distrito de Martins, único aglomerado com características urbanas dentro deste setor da bacia, possui um ponto de coleta de lixo que atende a demanda desta área.

A contaminação de mananciais e da água subterrânea também é uma consequência grave da apropriação urbana. Esta deterioração da qualidade da água surge a partir da lavagem das superfícies como casas, ruas e outros aparatos urbanos e a ligação clandestina de esgoto em redes pluviais constituem faces desta realidade (Tundisi, 2008).

Assim é delicada a condição do esgoto rural e urbano, pois a maior parte da bacia possui de fossas negras no meio rural e lançamentos irregulares de dejetos oriundos a partir do meio urbano. As fossas negras contaminam as águas subterrâneas e constituem um testemunho da antiga ocupação da bacia, onde tal prática foi estabelecida. Na região do córrego Feio o Departamento de Água e Esgoto de Patrocínio (DAEPA) tem realizado uma série de projetos para melhoria do cenário ambiental, entre eles a desativação de fossas negras e instalação das fossas sépticas. A vantagem das fossas sépticas esta no tratamento dos dejetos, no impedimento do contato de material contaminado com o solo e águas subterrâneas, na possiblidade de contenção de doenças de veiculação hídrica.

Outra fonte de poluição identificada na bacia se trata das granjas suínas. Foram apontadas cinco granjas, todas possuindo tratamento de efluentes. Esta é uma informação importante uma vez que este tipo de criação é considerada de grande impacto. Apesar das unidades de tratamento dos efluentes, existem reclamações dos habitantes em relação aos odores provenientes destes locais.

Quanto ao lançamento de esgoto nos cursos fluviais, nenhum canal da sub bacia do córrego Feio apresentou pontos de emissão. A situação é bem diferente nos cursos formadores do rio Dourados. Nestas áreas foram identificados três pontos de lançamento de efluentes, sendo dois rurais e um terceiro urbano. A contaminação das águas superficiais na bacia de estudo, significa a instalação de uma série de problemas relativos à indisponibilidade da água enquanto recurso para comunidades humanas. Os ecossistemas também tem seus serviços reduzidos ou interrompidos onde fauna e flora se desequilibram pela inserção de toxinas, 


\section{Periódica Eletrânica \\ Fórum Ambiental}

da Alta Paulista
Volume 11, Número 06, 2015

Planejamento e Gestão dos Recursos Hídricos

eutrofização da água, contaminação química, proliferação de determinada espécies em parelho com a supressão de outras (Tundisi e Tundisi, 2011).

Embora o DAEPA tenha construído uma estação de tratamento de esgoto (ETE) para o Bairro Serra Negra, existem emissões em pontos que não serão captados por esta estação. Deste modo a contaminação dos mananciais exige uma investigação para apontamento dos locais de emissão e medidas para eliminação dos focos ou tratamento dos resíduos. Uma outra ETE atende exclusivamente uma unidade prisional dentro da bacia (foto 3). Sem contudo possuir capacidade para atender futuras demandas de outras áreas.

Comparando as duas sub-bacias é nítido a maior concentração de problemas na região das nascentes do rio Dourados (tabela 1). O avanço significativo da mancha urbana de Patrocínio nos últimos 30 anos (Silva, 2014) e a composição de chácaras de final de semana (Silva e Allan Silva, 2012), no setor das nascentes do rio Dourados, revelam as causas destas diferenças entre as subbacias.

Foto 3: Alto curso da bacia do rio Dourados - área da Penitenciária. Ao fundo as serras do Gavião (direita) e do Cruzeiro (esquerda). Entre elas o exutório da área de pesquisa

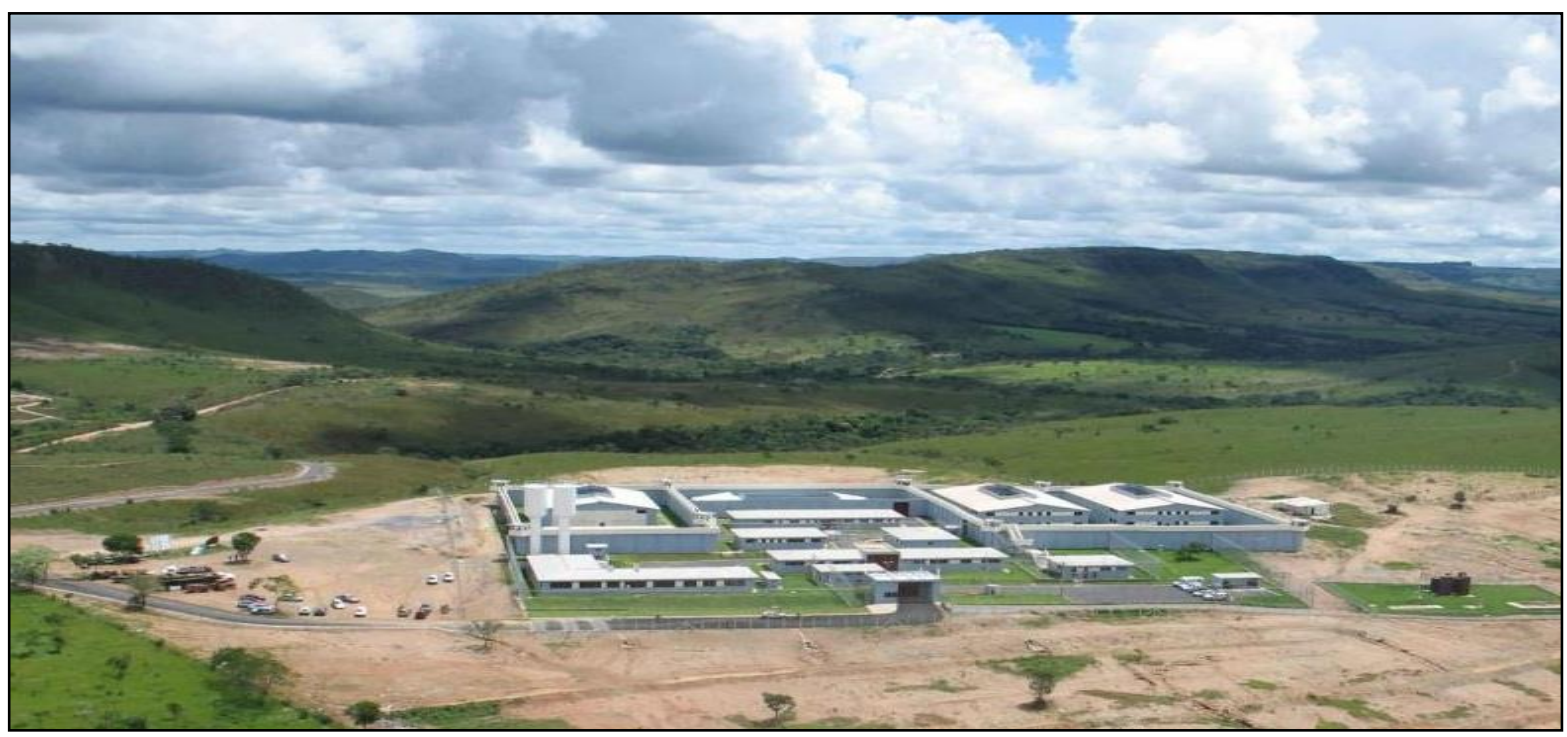

Fonte: Site Patrocínio online (2013) 


\section{Periódica Eletrânica

Tabela : Comparação dos elementos poluidores entre as sub-bacias estudadas

\begin{tabular}{lcc}
\hline Elementos da poluição & Sub bacia r. Dourados & Sub bacia do c. Feio \\
\hline Fossas Negras & 180 & 60 \\
Granjas & 5 & 0 \\
Pontos de descarte de lixo & 33 & 0 \\
Lançamento de efluentes & 3 & 0 \\
\hline
\end{tabular}

Fonte: Silva, 2015

Também o já citado cenário de abastecimento urbano contribui para a preservação da sub bacia do córrego Feio juntamente a condição histórica do uso e ocupação desta área. Enquanto a sub bacia do rio Dourados recebeu uma diversificada ocupação agrícola, o córrego Feio teve suas áreas atreladas a pecuária. Assim enquanto as nascentes do rio Dourados eram gradativamente alteradas e suas propriedades divididas (aumentando o número de moradias e pessoas), o córrego Feio manteve grandes áreas de pastagem com poucas instalações de novas sedes rurais. O fundo de vale acidentado também contribui para a manutenção das áreas de vegetação natural. $O$ resultado foi a menor ocupação nesta ultima área, se comparada a primeira com a preservação das áreas que se desenvolve a rede hidrográfica.

Como síntese desta analise ambiental tem-se o quadro 1 baseada na proposta do Ministério do Meio Ambiente, onde estão relacionados os indicadores da avaliação ambiental identificados durante o estudo na área.

Quadro 1: Indicadores conforme o MMA 2005 para a área total de estudo

\begin{tabular}{|c|c|}
\hline $\begin{array}{c}\text { Elementos de } \\
\text { Avaliação }\end{array}$ & Indicadores de impactos ambientais \\
\hline & Dimensão Físico-Biótica \\
\hline $\begin{array}{l}\text { Interferência } \\
\text { em aspectos } \\
\text { físicos: }\end{array}$ & $\begin{array}{l}\text { - Contaminação de solos por efluentes sanitários e agrícolas } \\
\text { - Existência de canais fluviais artificiais. }\end{array}$ \\
\hline $\begin{array}{l}\text { Interferência } \\
\text { em } \\
\text { Ecossistemas } \\
\text { Terrestres }\end{array}$ & $\begin{array}{l}\text { - Alteração no uso do solo, fauna e flora ameaçadas por contaminação do } \\
\text { solo e água, perda de áreas produtivas. } \\
\text { - Disseminação de pragar e animais peçonhentos em áreas com descarte } \\
\text { indevido de resíduos. }\end{array}$ \\
\hline
\end{tabular}




\begin{tabular}{|c|c|}
\hline $\begin{array}{l}\text { Interferência } \\
\text { em } \\
\text { Ecossistemas } \\
\text { Aquáticos }\end{array}$ & $\begin{array}{l}\text { - Variação de regime hidrológico, possibilidade de cheias mais intensas. } \\
\text { - Contaminação de mananciais devido ao aumento da carga de efluentes } \\
\text { sanitários; utilização de insumos agrícolas (fertilizantes e agrotóxicos), } \\
\text { suinocultura. } \\
\text { - Comprometimento da Qualidade da água } \\
\text { - Eutrofização }\end{array}$ \\
\hline & Dimensão Socioeconômica \\
\hline $\begin{array}{l}\text { Organização } \\
\text { do Território }\end{array}$ & $\begin{array}{l}\text { - } \text { Alteração na rede urbana (núcleos urbanos atingidos) } \\
\text { - } \quad \text { Especulação imobiliária (aumento do preço da terra). } \\
\text { - } \quad \text { Impacto sobre comunidades tradicionais }\end{array}$ \\
\hline
\end{tabular}

Fonte: Ministério do Meio Ambiente (2005). Org. SILVA, Renato Emanuel (2015)

O quadro revela a existência de impactos consideráveis na bacia estudada, a maior parte destes encontra-se na sub-bacia do rio Dourados que não contribui para o abastecimento urbano de Patrocínio, mas tem suas águas utilizadas por unidade rurais. A grande quantidade de problemas encontrados aponta para um histórico falho de estratégias ambientais junto ao desinteresse por parte dos órgãos públicos e a falta de conscientização das comunidades envolvidas. Logo é necessário uma mudança de postura, uma vez que os cenários futuros para a oferta hídrica tem suscitado debates sobre a indisponibilidade do recurso em diversas regiões do globo. Fator que eleva a importância da preservação dos mananciais para fins ecossistêmicos e também para o atendimento de comunidades humanas.

\section{CONCLUSÕES}

Esta pesquisa evidencia que uma mesma bacia pode apresentar cenários distintos quanto aos perfis de ocupação e os impactos ambientais resultantes. No caso do alto curso do rio Dourados a condição do setor da bacia que abastece a cidade de Patrocínio tem apresentado bons índices de preservação. Por outro lado o desinteresse em preservar a sub-bacia que abriga as nascentes do rio Dourados é nítida. Se trata de uma questão problemática pois a área que vem sofrendo impactos diversos poderia fornecer água para futuras demandas da cidade de Patrocínio. Contudo esta realidade se tornaria possível se os esforços hoje aplicados de 


\section{Periódica Eletranica

conservação para o córrego Feio fossem estendidos e adaptados aos demais cursos fluviais da bacia, respeitando as características de cada ambiente.

\section{REFERÊNCIAS}

CASSETI, V. Estrutura e gênese da compartimentação da paisagem de Serra Negra - MG. Goiânia: Ed. UFG, 1981.

DREW, D. Processos interativos homem-meio ambiente. Trad. João A. dos Santos. Rio de Janeiro: Bertrand Brasil, 1984.206

Hoekstra, A.Y. et Al. Manual de Avaliação da pegada Hídrica. São Paulo: EESC/USP, 2011

MACHADO, M.D.G. As unidades morfológicas e a estruturação da paisagem no município de Patrocínio - MG. Uberlândia: UFU, 2001. (Dissertação de Mestrado).

MALAGOLI, A. N. A qualidade de águas dos cursos fluviais formadores do rio Dourados em Patrocínio-MG (Monografia) Patrocínio, UNICERP, 2013

MENDES P.C. et Al Análise Climática e suas influências na Cultura Cafeeira no Município De Patrocínio-MG. Uberlândia: UFU, 2008

PRAXEDES et Al Enciclopédia biosfera, coleta de lixo na bacia hidrográfica do ribeirão da onça, minas gerais Centro Científico Conhecer - Goiânia, vol.6, n.9, 2010

SANTOS, R.F. Planejamento Ambiental: teoria e prática. São Paulo: Oficina de Textos, 2004.

SILVA, O.F. Planejamento Ambiental e ecologia da paisagem na validação de áreas alagadas e qualidade da água. Estudo de caso: bacia hidrográfica do rio Cotia (SP, BR). Tese de Doutorado - UNICAMP. Campinas, 2000

SILVA, R.E.; ALLAN SILVA, G. A importância do clima na instalação e produção cafeeira no Cerrado Mineiro: $O$ caso de Patrocínio no Alto Paranaíba (MG). X Simpósio de Geografia Climatológica 2012. Manaus. Disponível em:< www.revistageonorte.ufam.edu.br> Acesso em: $01 / 12 / 2012$

SILVA et al 2012 - Caracterização do regime pluviométrico da bacia do rio Dourados no Alto Paranaíba/MG. Revista GEONORTE, v. Clima, p, 850, 20126.

SILVA, R.E. Disponibilidade e demanda hídrica a partir da análise ambiental da região do alto curso do rio Dourados em Patrocínio (MG) (Dissertação de Mestrado) - Uberlândia: UFU, 2014

TUCCI, C.E.M.; MENDES, C.A. Curso de Avaliação Ambiental Integrada de Bacia. Brasília - DF: RHAMA. 2006

TUNDISI,J.G; TUNDISI, T.M-T. Recursos hídricos no Século XXI, São Paulo: Oficina de Textos, 2011

TUNDISI, J.G. Recursos Hídricos no futuro: problemas e soluções. Estudos Avançados. 22(63): 816, 2008

VELOSO, G. A. ; SILVA, R. E. ; SILVA, M. M. . Fotointerpretação De Imagens: Estudo De Caso Do Alto Da Bacia Hidrográfica Do Rio Dourados/ Patrocínio-MG Gabriel Alves Veloso, Renato. In: Marcos Esdras Leite. (Org.). Geotecnologias aplicadas aos estudos geográficos. 1ed.Montes Claros: Unimontes, 2013, v. 1, p. 47 